\title{
Effect of Blood Agar from Different Animal Blood on Growth Rates and Morphology of Common Pathogenic Bacteria
}

\author{
Tenny O. Egwuatu1, Folasade T. Ogunsola², Isi M. Okodugha², Bamiro Jide², \\ Damilola G. Arewa2 ${ }^{2}$ 0. A. Osinupebi ${ }^{2}$ \\ ${ }^{1}$ Department of Microbiology, Faculty of Science, University of Lagos, Akoka, Yaba, Lagos, Nigeria \\ ${ }^{2}$ Department of Medical Microbiology and Parasitology, College of Medicine, University of Lagos, Lagos, Nigeria \\ Email: tegwuatu@unilag.edu.ng
}

Received 23 October 2014; revised 29 November 2014; accepted 18 December 2014

Copyright (C) 2014 by authors and Scientific Research Publishing Inc.

This work is licensed under the Creative Commons Attribution International License (CC BY).

http://creativecommons.org/licenses/by/4.0/

(c) (i) Open Access

\begin{abstract}
Sheep and horse blood are the most commonly used blood for the isolation of microorganisms from human tissue and fluids. However, in many developing countries such as Nigeria, expired human blood from blood banks is still used despite the risk of exposure to HIV and other blood-borne infections, because it is easy to obtain. Blood agar made from blood of rams (similar to sheep), cows, chickens and goats, which are very common in Nigeria, were therefore evaluated. The isolation rates, colony size and morphology as well as haemolytic characteristics of common hospital pathogens such as Pseudomonas aeruginosa, Klebsiella pneumonae, Staphylococcus aureus, and Streptococcus spp, were tested on blood agar prepared from the different animal blood types. All reactions were observed at $24 \mathrm{hrs}$ and $48 \mathrm{hrs}$ respectively. Good growth was achieved by all isolates on rabbit, sheep and chicken blood agar though the best growth was achieved on ram blood agar but there was no significant variation in their morphology. There were differences in their abilities to distinguish haemolytic patterns. Beta Haemolytic Streptococci remained the same on all the blood agar, but the haemolysis of Staphylococci aureus and Pseudomonas aeruginosa varied on different media while haemolysis was least consistent on chicken and cow blood agar. Ram blood agar gave the best reactions in terms of good growth rates of organisms, good morphological characterization as well as good haemolytic reactions. Besides, it is easily available and large quantities of blood can be obtained. Despite the good qualities of ram blood agar observed in this study, however, there is a need for it to be tested further for its ability to support more fastidious organisms.
\end{abstract}

\section{Keywords}

Blood Agar, Haemolysis, Cultures, Bacterial Count 


\section{Introduction}

The concept of isolating micro-organisms in culture media has remained virtually unchanged since they were first developed by Robert Koch more than 100 years ago [1]. For a culture medium to be successful for growing the pathogens it must be able to provide all the essential nutrients, ions and moisture, to maintain the correct $\mathrm{pH}$ and osmotic pressure, and also be able to neutralize any toxic materials produced. From the onset it was recognized that the addition of blood or serum provided the nutritional factors present in the human body which were also required for the pathogens to grow [2]. Most specimens received in a clinical laboratory are therefore cultured on blood agar, because it supports the most fastidious clinically significant isolates.

Blood is added to blood agar base (small amount of natural carbohydrate, sodium chloride) to a concentration of $5 \%(\mathrm{v} / \mathrm{w})$ and is not only useful as a growth medium but allows the diagnosis of organisms on the basis of their haemolytic patterns [3]. In the United States defribrinated sheep blood is the blood of choice for bacteriological culture while horse blood is used in Europe. Defibrinated sheep blood is preferred because it inhibits the growth of the non-pathogenic commensal, Haemophillus haemolyticus, from throat cultures which may be mistaken for the clinically significant group A $\beta$-haemolytic Streptococci [4]. Blood from other animal species including humans have been used to demonstrate haemolysis to different degrees but expired human blood from blood banks is still used in Nigeria despite the known risk of blood borne infections such as Hepatitis B and HIV. In addition, some Streptococcus spp. produce alpha rather than beta haemolysis on human blood agar. It has been suggested that human blood may contain antibodies and anti-microbial agents which may also inhibit growth or cause false haemolysis [5]-[7].

Unfortunately, there is little information available about the effect of animal blood from other species on bacterial morphology and haemolysis. There is also a lack of comparative studies on horse and sheep blood [8]. In countries such as Nigeria, expired human blood from blood banks is often the most accessible source. Sometimes sheep blood is used but the species of sheep in Nigeria is different and its effect on microbial growth and other biochemical and morphologic characteristics has not been explored. As the risks of occupational exposure to blood-borne pathogens become more real and cannot be ignored, it has become imperative to explore other blood types to find a suitable, easily affordable source of blood for use in preparation of blood agar in Nigeria and other developing countries.

This study therefore describes and evaluates locally available animal blood types for their ability to support bacterial growth. It also identifies differences in colonial morphology and other growth characteristics, compares the growth rates of the isolates on the different blood types with that of sheep blood and human blood, and finally tries to determine the ease or limitations of obtaining these blood types in the society.

\section{Materials and Methods}

\subsection{Blood Collection}

Goat (Caprine), sheep (Ovine), cow (Bovine), were obtained from the Animal House at the College of Medicine, University of Lagos, while chicken (Avian) and rabbit, were bought from the local market. Questions were asked with regards to the health status of the animals and if any antibiotics had been used in the preceding month.

Twenty milliliters (20 mls) of blood was collected by cardiac puncture from the rabbit and chicken, and from the jugular veins of the goat, cow and sheep. Fresh human blood was obtained by venous puncture from colleagues and willing donors. All blood were collected aseptically in sodium citrate anticoagulant bottles and stored at $-4^{\circ} \mathrm{C}$, with a shelf life of three weeks. Laked horse blood (Oxoid) was also used.

\subsection{Source and Culture of Isolates}

Three different sets of stock cultures each of Pseudomonas aeruginosa, Staphylococcus aureus and Klebsiella pneumoniae were obtained from the Department of Medical Microbiology and Parasitology, College of Medicine, University of Lagos, while $\beta$-heamolytic Streptococcus was obtained from the throat, nasopharynx and sputum of volunteers. All isolates were sub-cultured on MacConkey and Blood agar (5\% human blood on blood agar base (Oxoid)). Isolates from sputum, throat and nasopharyngeal swabs were also cultured on chocolate agar, blood agar and crystal violet blood agar to obtain colonies of Streptococcus spp. Isolates were re-identified by standard procedures described by Cowan [9].

All catalase negative, beta heamolytic isolates were identified as Streptococci. The isolates were then grown 
in an overnight broth of tryptose soy broth and the turbidity diluted to match a 0.5 MacFarland standard prior to inoculation unto different blood agar plates. A tenfold serial dilution was prepared using Ringer's Solution as the diluent. $20 \mu \mathrm{l}$ of each dilution was then deposited unto each of the respective blood agar plates according to the method of Miles and Mistral [10]. All plates were incubated at $37^{\circ} \mathrm{C}$ for 24 and 48 hours respectively. Semi-quantitative analysis was carried out on each isolate inoculated on each of the different blood agar plates. The number of colonies counted was expressed as colony forming units ( $\mathrm{cfu} / \mathrm{ml}$. The morphological and cultural characteristics of each of the isolates, including heamolysis were noted for the different blood agar types.

\subsection{Statistical Analysis}

Statistical analysis was done by the student t-test at a confidence interval of 95\%. A probability of less than 0.05 was considered to represent a statistically significant difference.

\section{Results}

The effect of the different animal blood on the cultural and morphological characteristics of the various isolates was determined. There was no significant difference in the morphological and cultural characteristics of Klebsiella pneumoniae, non-hemolytic Streptococcus, and Staphylococcus aureus strains on the different animal blood types including human blood. The colour, pigmentation, elevation, consistency and shape of the colonies remained consistent with that reported in Bergey's Manual of Determinative Bacteriology (1993) [11], for up to the 48 hours incubation period.

\subsection{Bacterial Count}

The bacterial count is an indicator of the ability of the particular blood agar to support growth of the isolates. Klebsiella pneumoniae was found to grow less well on cow blood and horse blood, with a count of $0.6 \times 10^{7}$ $\mathrm{cfu} / \mathrm{ml}$. Difference in bacterial count was statistically significant with respect to human blood. There was also no statistically significant difference in the growth rates of Pseudomonas aeruginosa and Staphylococcus aureus on the all the blood agars. The growth of non-heamolytic Streptococcus on the other hand, was significantly reduced on all the different blood types when compared to human blood grew equally well on all the blood agar types (Table 1).

\subsection{Colony Size}

The colony sizes of all the isolates were compared with the standard size of the isolates as reported in Bergey's Manual [11]. There was no significant variation in the colony sizes from the standard sizes (Table 2).

\subsection{Heamolytic Pattern}

The heamolytic reaction of some of the isolates was observed and there were some differences in their abilities

Table 1. Comparison of bacterial count of the different organisms using the statistical differences on the different blood agar with respect to human blood.

\begin{tabular}{|c|c|c|c|c|c|c|c|}
\hline Isolates & $\begin{array}{c}\text { Human } \\
\text { Blood Agar }\end{array}$ & $\begin{array}{c}\text { Sheep Blood } \\
\text { Agar }\end{array}$ & $\begin{array}{c}\text { Cow Blood } \\
\text { Agar }\end{array}$ & $\begin{array}{c}\text { Goat Blood } \\
\text { Agar }\end{array}$ & $\begin{array}{c}\text { Rabbit Blood } \\
\text { Agar }\end{array}$ & $\begin{array}{l}\text { Laked Horse } \\
\text { Blood Agar }\end{array}$ & $\begin{array}{l}\text { Chicken } \\
\text { Blood Agar }\end{array}$ \\
\hline Klebsiella Pneumoniae & $1.73 \times 10^{7}$ & $\begin{array}{c}\text { (NS) } 0.0760 \\
1.93 \times 10^{8}\end{array}$ & $\begin{array}{c}(\mathrm{NS}) 0.000 \\
0.67 \times 10^{8}\end{array}$ & $\begin{array}{c}\text { (NS) } 0.4251 \\
1.81 \times 10^{8}\end{array}$ & $\begin{array}{c}\text { (NS) } 0.1693 \\
1.33 \times 10^{8}\end{array}$ & $\begin{array}{l}\text { (S) } 0.279 \\
1.30 \times 10^{8}\end{array}$ & $\begin{array}{c}\text { (NS) } 0.1711 \\
1.87 \times 10^{8}\end{array}$ \\
\hline Pseudomonas & $2.1 \times 10^{8}$ & $\begin{array}{c}\text { (S) } 0.0072 \\
3.3 \times 10^{8}\end{array}$ & $\begin{array}{c}\text { (NS) } 0.3552 \\
1.8 \times 10^{8}\end{array}$ & $\begin{array}{c}\text { (S) } 0.0064 \\
3.1 \times 10^{8}\end{array}$ & $\begin{array}{l}\text { (S) } 0.000 \\
5.0 \times 10^{8}\end{array}$ & $\begin{array}{c}\text { (NS) } 0.1681 \\
2.5 \times 10^{8}\end{array}$ & $\begin{array}{c}\text { (S) } 0.0088 \\
3.2 \times 10^{8}\end{array}$ \\
\hline Beta-Haemolytic Strep. & $1.6 \times 10^{8}$ & $\begin{array}{c}\text { (S) } 0.0052 \\
2.5 \times 10^{8}\end{array}$ & $\begin{array}{c}\text { (NS) } 0.3552 \\
1.8 \times 10^{8}\end{array}$ & $\begin{array}{c}\text { (NS) } 0.1049 \\
7.4 \times 10^{8}\end{array}$ & $\begin{array}{c}\text { (S) } 0.0216 \\
2.3 \times 10^{8}\end{array}$ & $\begin{array}{c}\text { (NS) } 0.2137 \\
8.1 \times 10^{8}\end{array}$ & $\begin{array}{c}\text { (NS) } 0.1492 \\
8.3 \times 10^{8}\end{array}$ \\
\hline Staphylococcus aureus & $7.7 \times 10^{8}$ & $\begin{array}{c}\text { (NS) } 0.5733 \\
7.5 \times 10^{8}\end{array}$ & $\begin{array}{c}\text { (NS) } 0.1248 \\
8.2 \times 10^{8}\end{array}$ & $\begin{array}{c}\text { (NS) } 0.4626 \\
7.4 \times 10^{8}\end{array}$ & $\begin{array}{c}\text { (NS) } 0.2070 \\
8.4 \times 10^{8}\end{array}$ & $\begin{array}{c}(\mathrm{NS}) \\
8.2137 \\
8.1 \times 10^{8}\end{array}$ & $\begin{array}{c}\text { (NS) } 0.1492 \\
8.3 \times 10^{8}\end{array}$ \\
\hline Non-Haemolytic Strep & $125 \times 10^{8}$ & $\begin{array}{l}\text { (S) } 0.000 \\
8.0 \times 10^{8}\end{array}$ & $\begin{array}{l}\text { (S) } 0.000 \\
1.0 \times 10^{8}\end{array}$ & $\begin{array}{c}\text { (S) } 0.0002 \\
6.8 \times 10^{8}\end{array}$ & $\begin{array}{c}\text { (S) } 0.0000 \\
1.9 \times 10^{8}\end{array}$ & $\begin{array}{c}\text { (S) } 0.0001 \\
6.4 \times 10^{8}\end{array}$ & $\begin{array}{c}\text { (S) } 0.0001 \\
6.5 \times 10^{8}\end{array}$ \\
\hline
\end{tabular}

KEY: P < 0.05; NS = Not Significant; S = Significant. 
Table 2. Colony size of isolates at 24 and 48 hours colony size ( $\mathrm{mm})$ on blood agar.

\begin{tabular}{cccccccccccccccccc}
\hline \multirow{2}{*}{ Isolates } & \multicolumn{2}{c}{ Human } & \multicolumn{2}{c}{ Sheep } & \multicolumn{2}{c}{ Chicken } & \multicolumn{2}{c}{ Cow } & \multicolumn{2}{c}{ Rabbit } & \multicolumn{3}{c}{ Goat } & \multicolumn{2}{c}{ Laked Horse } \\
\hline & $24 \mathrm{~h}$ & $48 \mathrm{~h}$ & $24 \mathrm{~h}$ & $48 \mathrm{~h}$ & $24 \mathrm{~h}$ & $48 \mathrm{~h}$ & $24 \mathrm{~h}$ & $48 \mathrm{~h}$ & $24 \mathrm{~h}$ & $48 \mathrm{~h}$ & $24 \mathrm{~h}$ & $48 \mathrm{~h}$ & $24 \mathrm{~h}$ & $48 \mathrm{~h}$ \\
\hline Klebsiella pneumoniae & 2.5 & 5.0 & 2.5 & 4.0 & 2.5 & 4.0 & 2.0 & 4.0 & 2.5 & 54.0 & 2.5 & 4.0 & 2.5 & 5.0 \\
Non-Haemolytic Strep & 0.5 & 0.5 & $<0.5$ & $<0.1$ & 0.5 & 1.0 & 0.5 & 0.5 & 0.5 & 0.5 & 0.5 & 0.5 & $<0.5$ & $<1.0$ \\
Pseudomonas aeruginosa & 1.0 & 1.5 & 1.5 & 3.5 & 1.5 & 2.5 & 1.5 & 3.5 & 1.5 & 3.5 & 1.5 & 3.5 & 1.0 & 1.5 \\
Beta-Heamolytic Strep & $<1.0$ & $<1.0$ & $<1.0$ & $<1.0$ & $<1.0$ & $<1.0$ & $<1.0$ & $<1.0$ & $<1.0$ & $<1.0$ & $<1.0$ & $<1.0$ & $<1.0$ & $<1.0$ \\
Staphylococcus aureus & 1.0 & 1.5 & 1.0 & 1.5 & 1.0 & 1.5 & 1.0 & 1.5 & 1.0 & 1.5 & 1.0 & 1.5 & 1.0 & 1.5 \\
\hline
\end{tabular}

to distinguish haemolytic patterns. Beta-Haemolytic Streptococci remained the same on all the blood agars, while the $\alpha$-haemolysis observed in Staphylococci aureus was not seen on chicken blood agar where it was $\alpha$ haemolytic. Pseudomonas aeruginosa was $\beta$-haemolyic on cow agar, $\alpha$-haemolytic on both goat and rabbit agar. On human and sheep blood agar, Pseudomonas aeruginosa was only $\alpha$-haemolytic at $24 \mathrm{~h}$ incubation and became $\beta$-haemolyic at $48 \mathrm{~h}$. Haemolysis was least consistent on chicken and cow blood agar.

\section{Discussion}

All the blood agars prepared from animals and man supported the growth of all the isolates and there was no significant difference in the morphology and cultural characteristics on the various blood agar types. This was further confirmed by comparing with descriptions from Bergey's Manual [10]. This is comparable to a study in Australia and Fiji which compared blood agar prepared by using citrated sheep blood, defibrinated non-citrated sheep blood, citrated human blood agar and defribrinated, non-citrated horse blood agar [12]. However substantially smaller colony sizes and absent or minimal heamolysis were noted on human blood agar [13].

Though sheep, rabbit and chicken blood agar appeared to support growth better than human blood agar, there were some variations in their heamolytic reactions of the isolates on the different blood agar types. Cow and Chicken blood agar were found to give inconsistent heamolytic reactions with some isolates and may therefore give inconsistent results in the laboratory. This was observed in the case of cow blood agar in which an observation of beta heamolytic reaction was made at both 24 and 48 hours incubation period for Pseudomonas aeruginosa as against alpha heamolysis at 24 hours on sheep and human blood, while chicken blood agar gave an alpha heamolytic reaction at both 24 and 48 hours incubation period as against beta heamolysis maintained on sheep and human and the other blood agar types.

Although cow blood is easily available, the variability of the heamolytic reactions by some of the organisms and the fact that it did not support adequate growth of Klebsiella pneumoniae, which happens to be one of the most common organisms associated with hospitals acquired infections in Nigeria [14]. Its use might not therefore be able to serve the purpose for which it is sought. Chicken on the other hand was able to support the growth of all the isolates but gave variable heamolytic reactions.

Ram which is related to sheep supported the growth of all isolates and including their heamolytic reactions. It is also easily available and affordable costing between ten to five thousand Naira which is equivalent to fifty to eighty dollars. Also ability to obtain large volumes (125 - $200 \mathrm{mls})$ of blood at each draw makes it the best alternative to human blood for bacteriological studies. Moreover, it has been suggested that citrated sheep blood is a better alternative to citrated human blood for isolation of organisms [7] [13], other studies have demonstrated that defribinated pig blood and goat blood are suitable alternatives for medium supplement for Streptococcus pneumonia [12]. However irrespective of the intrinsic ability of the other blood agar types (cow, chicken, goat, rabbit), it became apparent that despite their easy availability for human consumption, obtaining their blood for bacteriological use was difficult. This was, in part, due to the fact that blood is considered sacred and many butchers believe that blood should not be kept but buried in the soil or used for ritual purposes.

There was also the problem of collecting sufficient blood from the smaller animals like the rabbit and chicken as not more than $10-15 \mathrm{mls}$ could be obtained without causing serious harm to the animal. For the larger animals like the cow, goat and sheep about $125 \mathrm{mls}$ could be obtained at a time, though it would be necessary to determine how often these animals can be bled. Cost of the animals need also to be taken into consideration, for 
example, rabbit is much more expensive and less common than chicken, so despite its ability to support growth of most bacteria, it will be expensive to use routinely.

Finally, there is a need to put in place a machinery to cultivate animals for the purpose of blood collection and to defribrinate their blood on a large scale specifically for bacteriological purposes.

There are very few published studies comparing the use of animal blood with human blood used in the diagnostic laboratory. We were only able to find two reports and these were not performed in Africa [7] [13]. There is a need to do more work on comparison between sheep/ram and goat blood agar for use in the diagnostic bacteriology laboratory in Nigeria.

\section{References}

[1] Bridson, E.Y. (1990) Media in Microbiology. Reviews in Medical Microbiology, 1, 1-9.

[2] Greenwood, D., Slack, R.C.B. and Peutherer, J.F. (1997) Medical Microbiology: A Guide to Microbial Infections: Pathogenesis, Immunity, Laboratory Diagnosis and Control. 15th Edition, Churchill Livingstone, London.

[3] Davis, D., Dulbeco, L., Eisen, N.H. and Ginsberg, S.H. (1980) Microbiology Including Immunology and Molecular Genetics. Harper International Edition, Harper \& Row, New York.

[4] Philips, E. and Nash, P. (1985) Culture Media. In: Leinnet, E.H., Balows, A., Hauster Jr., W.J. and Shadony, H.D., Eds., Manual of Clinical Microbiology, 6th Edition, American Society of Microbiology, Washington DC, 1051-1092.

[5] Marmion, B.P. and Tonkin, R.W. (1972) Control of Hepatitis in Dialysis Units. British Medical Bulletin, 28, 169-179.

[6] Nash, P. and Krent, M.M. (1991) Culture Media. In: Balows, A., Hauster Jr., W.J. and Herman, K.L., Eds., Manual of Clinical Microbiology, 5th Edition, American Society of Microbiology, Washington DC, 1268.

[7] Johnson, D.R., Kaplan, E.L., Sramek, J., Bicova, R., Haylicek, J., Havilockova, H., Moliova, J. and Kriz, P. (1996) Laboratory Diagnosis of Group A Streptococcal Infections. World Health Organization, Geneva.

[8] Hoppe, J.E. and Schlangenhauf, M. (1989) Comparison of Three Kinds of Blood and Two Incubation Atmospheres for Cultivation of Bordetella pertussis on Charcoal Agar. Journal of Clinical Microbiology, 27, 2115-2117.

[9] Barrow, G.I. and Feltham, R.K.A., Eds. (1993) Cowan and Steel’s Manual for Identification of Medical Bacteria. 3rd Edition, Cambridge University Press, Cambridge. http://dx.doi.org/10.1017/CBO9780511527104

[10] Miles, A.A., Irwin, J.O. and Mistra, S.S. (1938) The Estimation of the Bactericidal Power of the Blood. Journal of Hygiene, 38, 732-749. http://dx.doi.org/10.1017/S002217240001158X

[11] Holt, J.G., Kreig, N.R., Sneath, P.H.A., Staley, J.T. and Williams, S.T., Eds. (1994) Bergey’s Manual of Determinative Bacteriology. 9th Edition, Williams and Wilkins, Philadelphia.

[12] Anand, C.R., Gordon, A., Shaw, H., Fonseca, K. and Olsen, M. (2000) Pig and Goat Blood as Substitutes for Sheep Blood in Blood Supplemented Agar Media. Journal of Clinical Microbiology, 38, 591-594.

[13] Rusell, F.M., Biribo, S.S.N., Selvaraj, G., Mulhollad, E., Carapetis, J.R., et al. (2006) As a Bacterial Culture Medium, Citrated Sheep Blood Is a Practical Alternative to Citrated Human Blood Agar in Laboratories of Developing Countries. Journal of Clinical Microbiology, 44, 3346-3351. http://dx.doi.org/10.1128/JCM.02631-05

[14] Efem, S.E., Aja, A. and Inyang, U. (1986) Surgical Wound Infection Rate in Calabar, University Teaching Hospital. West Africa Journal of Medicine, 5, 61-68. 
Scientific Research Publishing (SCIRP) is one of the largest Open Access journal publishers. It is currently publishing more than 200 open access, online, peer-reviewed journals covering a wide range of academic disciplines. SCIRP serves the worldwide academic communities and contributes to the progress and application of science with its publication.

Other selected journals from SCIRP are listed as below. Submit your manuscript to us via either submit@scirp.org or Online Submission Portal.
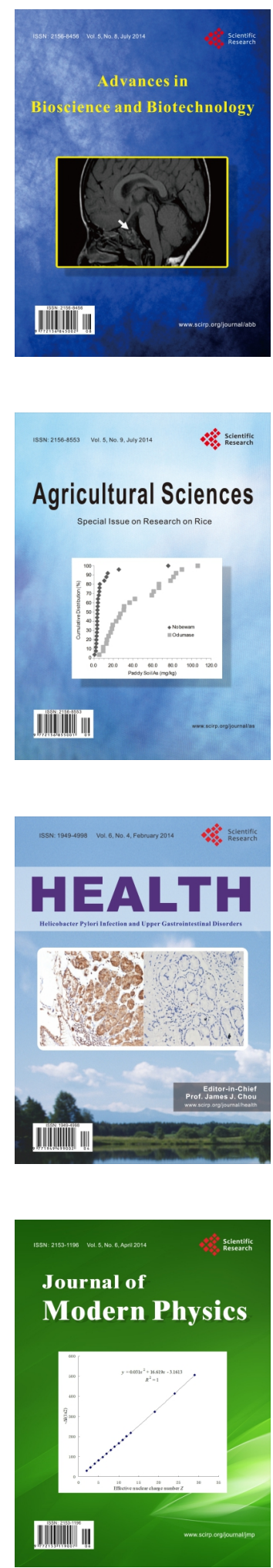
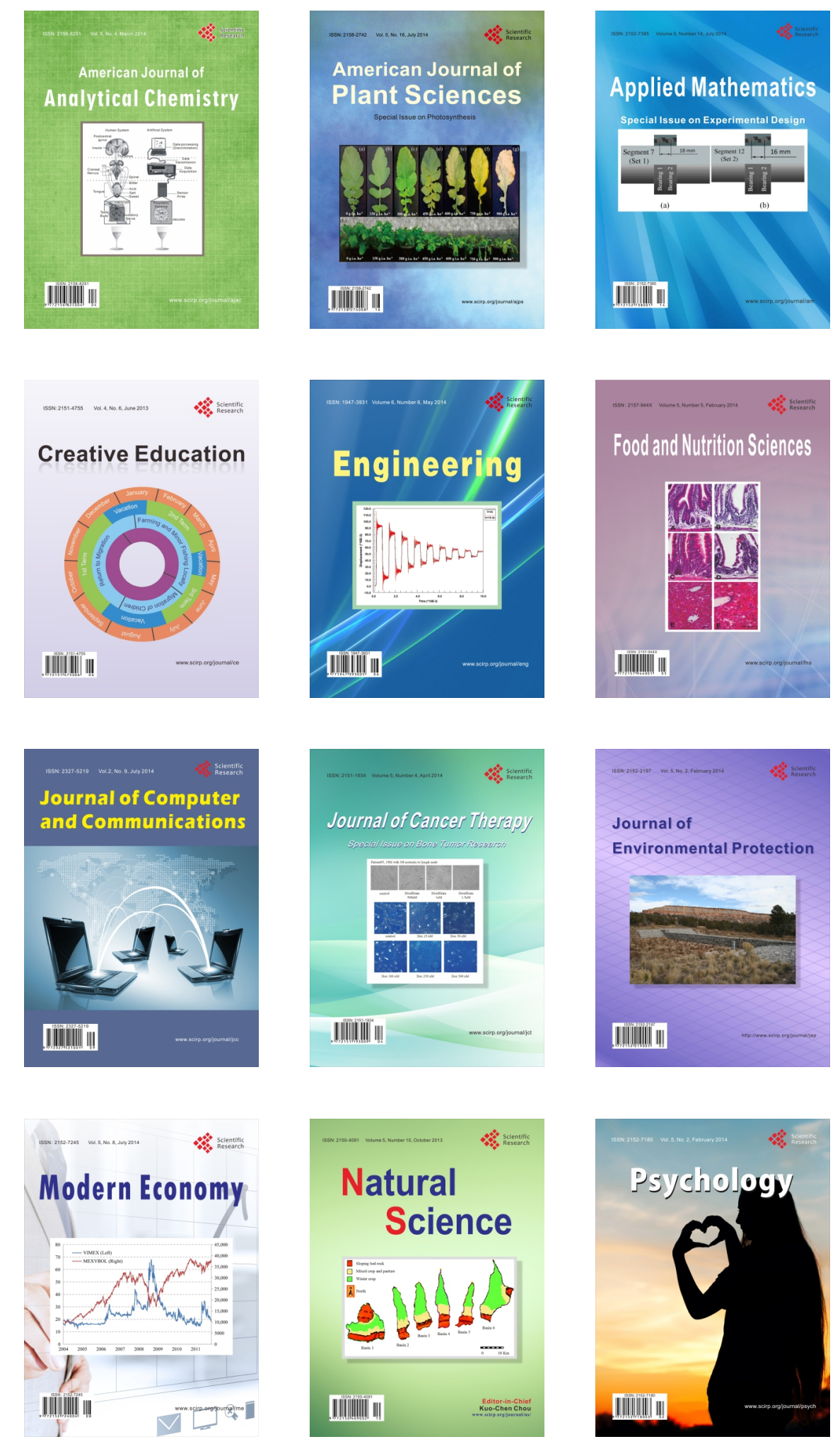